\title{
Effect of Median Nerve Mobilization and Median Nerve Self-Mobilization on Median Motor Nerve Conduction Velocity
}

\author{
Misook Ha, $\mathrm{PT}^{1)}$, Youngmin Son, $\mathrm{PT}^{1)}$, Dongwook Han, PhD, $\mathrm{PT}^{1)}$ \\ 1) Department of Physical Therapy, College of Medical and Life Science, Silla University: 100 \\ Silladaehakgil, Sasanggu, Busan, 617-736 Republic of Korea. \\ TEL: +82 51-999-6238,FAX: +82 51-999-5176,E-mail:dwhan@silla.ac.kr
}

\begin{abstract}
Purpose] This study examined the difference in nerve conduction velocity (NCV) between two groups: in one group, a physical therapist performed median nerve mobilization (MNM) for the subjects of one group, and in the other group, the subjects received training and practice MNM for themselves. Based on the results, the therapeutic basis of MNM was examined, and the usefulness of self-MNM education was tested. [Subjects] Twenty healthy female college students without symptoms or signs of peripheral neuropathy were the subjects. [Method] The subjects of both groups received a median motor nerve conduction study before and after MNM. While keeping the elbow joint and wrist joint extended, MNM was maintained for 15 seconds, followed by a 10 second break. This was repeated three times. [Results] In the wrist-elbow section, NCV increased in the MNM group but did not significantly change in the self-MNM group. NCV rose in the MNM group but fell in the self-MNM group. For the elbow-axilla section, NCV increased in the MNM group but did not significantly change in the self-MNM group. NCV rose in the MNM group but fell in the self-MNM group. [Conclusion] The analysis of the results showed that a physical therapist's application of MNM was more effective than self-MNM at increasing nerve conduction velocity.

Key words: Median nerve mobilization, Median nerve self-mobilization, Median motor nerve conduction velocity
\end{abstract}

(This article was submitted Mar. 22, 2012, and was accepted Apr. 24, 2012)

\section{INTRODUCTION}

The median nerve fiber starts from the superior, middle, and inferior trunks of the brachial plexus, and the inner and outer cords run through the forearm, through the underside of the carpal tunnel, and spread sensory nerves toward the palm of a hand ${ }^{1)}$. Impairment of the median nerve causes many difficulties in activities of daily living (ADL) because people frequently use their hands, and deterioration of the senses increases the risk of damage. Damage to the nervous system, which can be inflicted by many causes, might obstruct nerve conduction, which is a unique function of the nervous system, possibly leading to sensory disturbance or motor disturbance ${ }^{2)}$

Nerve mobilization (NM) is one of the treatment methods for peripheral neuropathy, and it involves very specific movements to restore an adequate level of flexibility to the nervous system in the vertebra, upper extremities, and lower extremities ${ }^{3)}$. The concept of nervous system mobility is that the nervous system should be adequately stretched and contracted in order to maintain normal muscular tension and ensure a proper range of mobility. This is called neurodynamics, a term that integrates the biomechanical, physiological, and formal functions of the nervous system ${ }^{4)}$. In terms of therapy, NM has been developed by physical therapists. Also, Butler further established specific theories, clinical test methods, and the mobility of the nervous system in his publications.

In NM, nerve conduction is accelerated by enhancing the axonal transport system, and blood flow to the nerves is increased by lessening the pressure within the nerves. This is closely related to the recovery of soft tissues, including the nerves and muscles ${ }^{5)}$. Korr argued that nerve disturbance and responses to therapy are closely related to the axonal transport system ${ }^{6}$. Maitland claimed that the NM technique helps to mitigate the pain transmitted by nerve fibers which is related to inflammation and dysfunction of nerve tissues, and that it reduces neural compression and friction in the nerves by increasing the compliance of peripheral nerves ${ }^{5)}$. Similarly, Butler argued that the purpose of median nerve mobilization (MNM) is to enhance the mobility of the median nerves and reduce the mechanosensitivity of the nervous system, because it enhances the compliance of the nervous system ${ }^{7}$. This helps to mitigate pain and widen the range of motion (ROM); it also improves the mechanical adaptability of the nervous system allowing the body to move with less resistance ${ }^{6}$. In addition, NM reduces scar tissues within the nervous system, directly reducing pain ${ }^{8}$. Thus, the peripheral nervous system should be adequately stretched to maintain a normal level of muscular tension and $\mathrm{ROM}^{6)}$.

However, an issue with NM is that it must be performed 
Table 1. General characteristics of subjects $(n=20)$

\begin{tabular}{lll}
\hline & MNM group (10) & Self-MNM group (10) \\
\hline Age (year) & $21.40 \pm 1.27$ & $20.90 \pm 0.88$ \\
Height $(\mathrm{cm})$ & $160.30 \pm 7.38$ & $161.80 \pm 3.68$ \\
Weight $(\mathrm{kg})$ & $54.10 \pm 6.89$ & $53.00 \pm 7.82$ \\
Pre-Wrist-Elbow (m/s) & $58.71 \pm 4.61$ & $59.71 \pm 1.96$ \\
Pre-Elbow-Axilla (m/s) & $63.80 \pm 3.02$ & $63.42 \pm 2.50$ \\
\hline
\end{tabular}

MNM : Median Nerve Mobilization

by a physical therapist. Patients receive training regarding NM so that they can continue the stretching exercise after the treatment is over. However, not many studies have been undertaken to test the effectiveness of the training.

In this context, this study examined the difference in nerve conduction velocity (NCV), which indicates the state of the peripheral nerves, between two groups: a physical therapist performed NM for the subjects of one group, and in the other group, the subjects received training and practiced MNM for themselves. Based on the results, we investigate the usefulness of self-MNM education.

\section{SUBJECTS AND METHODS}

For this research, twenty healthy female college students from S University in Busan were recruited. They understood the research objective and agreed to participate in the experiment. They were free of the symptoms and signs of peripheral neuropathy. The nerve mobilization group had an average age of 21.4 years, an average height of $160.30 \mathrm{~cm}$, and an average weight of $54.10 \mathrm{~kg}$, and the self-nerve mobilization group, had an average age of 20.9 years, an average height of $161.80 \mathrm{~cm}$, and an average weight of $53.00 \mathrm{~kg}$.

Prior to the experiment, median motor nerve conduction velocities between the wrist and the elbow were $58.71 \mathrm{~m} / \mathrm{s}$ for the MNM group and $59.71 \mathrm{~m} / \mathrm{s}$ in the self-MNM group. For the elbow-axilla section, the velocity was $63.80 \mathrm{~m} / \mathrm{s}$ in the MNM group, and $63.42 \mathrm{~m} / \mathrm{s}$ in the self-MNM group. The normal range for the two sections are over $50.5 \mathrm{~m} / \mathrm{s}$ and over $51.2 \mathrm{~m} / \mathrm{s}$, and subjects in both the groups showed velocities higher than the minimum value ${ }^{9,10)}$. There were no significance differences between the two groups (Table 1).

The twenty participants were assigned to either the MNM group or the self-MNM group, using a table of random numbers. The subjects in both groups received a median motor nerve conduction study of the left upper extremity before and after MNM.

In the MNM group, the subjects lay down in a supine position and kept the neck and the trunk in the neutral position. The shoulder joint was placed on the examiner's left thigh at 90 degrees of abduction, with the elbow joint at 90 degrees of flexion. The examiner depressed the subject's shoulder girdle with his or her left hand, extended the left wrist joint, and supinated the forearm with his or her right hand. At the same time, external rotation was applied to the shoulder joint, and the elbow joint was slowly extended. If the subject showed an adequate level of tension, lateral flexion was slowly performed for the neck in the opposite direction, examining the subject's reaction so as not to cause excessive pain. For MNM, the method of Coppieters and Alshami was used with modification of time and the number of applications. While keeping the elbow joint and wrist joint extended, MNM was maintained for 15 second, followed by a 10 -second break. This was repeated three times ${ }^{11)}$.

For the self-MNM Group, a physical therapist explained and demonstrated the MNM method. Then, the subjects lay down in the supine position, with the neck and trunk in the neutral position. The subjects were asked to practice MNM on themselves. Like the other group, they maintained MNM for 15 seconds, followed by a 10 -second break. This was repeated three times. To reduce inter-rater error among the therapists, one physical therapist (PT) with over 5 years of clinical experience conducted the experiment.

Electromyography (EMG; MEP-9200k 2007, Nihon Kohden, Japan) was used for the median motor nerve condition study. The subjects were asked to lie down, and their upper left limbs were kept at 45 degrees of abduction for the test. In the nerve conduction study, the peripheral parts of the limbs which were subject to the ambient temperature were used; the response varied among individual. Henrikson reported that NCV fell $2.4 \mathrm{~m} / \mathrm{s}$ when the muscle temperature decreased by $1{ }^{\circ} \mathrm{C}^{12}$. Johnson reported the velocity slowed by $5 \%$ under the same conditions ${ }^{13)}$. According to Halar, cutaneous temperature, temperatures in the visceral fat layer, and muscle temperature show linear correlation, and thus, NCV can be adjusted by measuring the cutaneous temperature ${ }^{14)}$.

Since measuring muscle temperature can be complex and painful, NCV was measured by keeping cutaneous temperature stable based on Halar's study. To keep cutaneous temperature within a normal range of $30-37^{\circ} \mathrm{C}$, a hot pack was wrapped around the subject's upper left extremity, and cutaneous temperature was adjusted to $34.1^{\circ} \mathrm{C}$ for all subjects. For the median motor nerve conduction study, an activation recording electrode was attached to the muscle belly of the abductor pollicis brevis, and a recording electrode was attached to the tendon of the abductor pollicis brevis. Nerve stimulation was administered at the wrist joint, the elbow joint, and the axilla area ${ }^{9,15}$. The ambient temperature of the lab environment was maintained at $21-23^{\circ} \mathrm{C}$. To minimize measurement errors, the nerve conduction study was conducted in the Electrophysiologic Tests Room of D Hospital, Busan, by an examiner with over 15 years of experience. 
Table 2. Median motor nerve conduction velocity and its changes in the MNM group and self-MNM group $(n=20)$ volunteers

\begin{tabular}{llll}
\hline & & Pre-MNM & Post-MNM \\
\hline \multirow{2}{*}{ W-E } & NM group* & $58.71 \pm 4.61$ & $60.70 \pm 3.72 \dagger$ \\
& Self-NM group & $59.71 \pm 1.96$ & $59.62 \pm 1.99$ \\
\hline \multirow{2}{*}{ E-A } & NM group* & $63.80 \pm 3.02$ & $65.37 \pm 3.05 \dagger$ \\
& Self-NM group & $63.42 \pm 2.50$ & $62.43 \pm 2.31$ \\
\hline
\end{tabular}

Mean \pm SD. *: Paired t-test $(\mathrm{p}<0.05) .^{\dagger}:$ ANCOVA test, MNM group $\neq$ self-MNM group $(\mathrm{p}<0.05)$. W-E : Wrist-Elbow. E-A : Elbow-Axilla. MNM group : Median Nerve Mobilization group

The Shapiro-Wilk test was conducted to verify the normality of the data, which were collected from only a small number of subjects. The test result was satisfactory, and parametric tests were conducted accordingly. To examine the general characteristics of the subjects and the differences in median motor nerve conduction velocity (NCV) before MNM, the independent samples t-test was conducted. In order to examine the effect of MNM and self-MNM on median motor NCV, paired samples t-test was conducted to, compare the velocity before and after the mobilization therapy. Also, ANCOVA was conducted to examine the difference between the two groups. SPSSWIN (ver. 18.0) was used for the statistical analysis, and a significance level of $\alpha=0.05$ was chosen.

\section{RESULTS}

The median motor nerve conduction velocity, its changes after the mobilization therapy, and the effects of MNM and self-MNM were analyzed. For the wrist-elbow section, the average velocity increased from $58.71 \mathrm{~m} / \mathrm{s}$ to $60.70 \mathrm{~m} / \mathrm{s}$ in the MNM group $(\mathrm{p}<0.05)$. In comparison, the average velocity fell from $59.70 \mathrm{~m} / \mathrm{s}$ to $59.62 \mathrm{~m} / \mathrm{s}$ in the self-MNM group, although the change was not statistically significant. That is, the two groups showed variance $(\mathrm{p}<0.05)$, because the velocity increased for the MNM group and decreased for the self-MNM group. For the elbow-axilla section, the average velocity rose from $63.80 \mathrm{~m} / \mathrm{s}$ to $65.37 \mathrm{~m} / \mathrm{s}$ in the MNM group $(\mathrm{p}<0.05$ ), while it fell slightly, from $63.42 \mathrm{~m} / \mathrm{s}$ to $62.43 \mathrm{~m} / \mathrm{s}$, in the self-MNM group. Regarding the extent of the changes in median motor nerve conduction velocity, the two groups showed differences because the conduction velocity rose in the MNM group and fell in the self-MNM group $(\mathrm{p}<0.05)$ (Table 2).

\section{DISCUSSION}

The primary function of the nervous system is to transmit nervous stimulation, and it is essential to maintain the adequate length of the central and peripheral tracks so that a person can maintain the various postures required in ADL and move the body without blocking nerve conduction ${ }^{3)}$. Damage to the nervous system, which can be inflicted by many causes, might interfere with nerve conduction, which is a peculiar characteristic of the nervous system, and possibly lead to sensory or motor disturbance ${ }^{2)}$. The nerve conduction study is one of the tools used to examine the areas of nerve damage and the degree of damage in patients with peripheral neuropathy ${ }^{16)}$.

The nerve conduction study is a convenient diagnostic tool for lower motor neuron diseases, especially peripheral neuritis. It objectively assesses nerve root diseases and the accompanying pathological and physiological changes ${ }^{1)}$. Decrease in the conduction velocity of the peripheral nerve and increase in the latency is an important electrophysiological indicator. For the upper limbs, a nerve conduction study of the median nerve and the ulnar nerve is most commonly used.

To examine the effect of nerve mobilization, NCV was measured. Among the median, ulnar, and radial nerves, median nerve mobilization (MNM) was applied based on the study of Kleinrensink which reported that MNM could induce higher tension in the upper limbs ${ }^{17)}$. NCV was measured to discover whether MNM enhanced the functions of the nerves. In general, a nerve conduction study is greatly affected by temperature. Bolton argued that when cutaneous temperature fell by $1{ }^{\circ} \mathrm{C}$, the latency of the median nerve action potential slowed by 0.07 msfor retrograde conduction and $0.11 \mathrm{~ms}$ for orthodromic conduction ${ }^{18)}$

In the present study, the subjects' arms were wrapped in hot packs to keep the cutaneous temperature at $34.1{ }^{\circ} \mathrm{C}$ during the nerve conduction study. The purpose of this was to prevent a falling temperature from lengthening distal latency, and affecting the ion permeability of Ranvier's node and the reaction to voltage.

Upper limb nerve mobilization (NM) is a widely used treatment method for dysfunctions of the upper limbs. Butler reported that upper limb NM suppresses spasm and facilitates muscular tension and the overall recovery of patients with upper limb dysfunctions due to brain damage ${ }^{3)}$. Park JW et al. also reported that upper limb NM leads to significant differences in the restoration of muscular power, spasticity, and functional recovery of post-stroke hemiplegic patients ${ }^{19,20)}$.

Anderson reported that upper limb NM mitigated pain for the patients with Quervain's tendinitis ${ }^{21)}$. Also, Rozmaryn et al. argued that the steady application of NM mitigates edema, one of the causes of carpal tunnel syndrome (CTS), and improves nerve extensibility and circulation to reduce the inner pressure of the carpal tunnel ${ }^{22)}$. Similarly, Kim MK et al. performed MNM for CTS patients and reported that it reduce pressure in the carpal tunnel, improved NCV and grip strength, and alleviated pain ${ }^{23}$. Yoon YD reported that MNM led to significant improvement in CTS patients' grip strength and pain level ${ }^{24)}$.

Previous studies have proposed that NM is effective at enhancing nerve function. The findings of the present study support this proposal because a physical therapist's application of NM improved the conduction velocity of the median nerve $(\mathrm{p}<0.05)$. In NM, tension is placed upon the nerve system, which contracts the cross-sectional area of the nerve, closing small blood vessels that cross the nerve epineurium, and thus increasing blood flow to the neurofibers $^{7)}$. 
In this process, the axonal transport system increases the flexibility of the contracted median nerve and structures around the joints, accelerating NCV. Therefore, NM is an effective treatment method for patients with peripheral neuropathy. NCV did not increase in the self-MNM group, which indicates that self-treatment was not effective at stretching the nerve. The self-MNM group adopted an open kinetic chain exercise, which obstructed hyperextension of the wrist. Also, the subjects could not depress the shoulder girdle by themselves. Since hyperextension of the wrist is required for nerve mobilization, further research is called for to address these problems in developing self-MNM methods and assessing their effectiveness.

\section{REFERENCES}

1) Sethi RK, Thompson LL: The electromyographer's handbook; Boston: Little Brown and Company, 1989.

2) Nee RJ, Butler DS: Management of peripheral neuropathic pain: integrating neurobilology, neurodynamics and clinical evidence. Phys Ther Sport, 2006, 7: 36-49. [CrossRef]

3) Butler DS: Mobilization of the Nervous System; London: Churchill Livingstone, 1991, pp 147-159.

4) Shacklock M: Neurodynamics. Physiotherapy, 1995, 81: 9-16. [CrossRef]

5) Maitland GD: The slump test: examination and treatment. Aust J Physiother, 1985, 31: 215-219.

6) Korr IM: The Neurobiologic Mechanisms in Manipulation Therapy; New York: Plenum Press, 1978.

7) Butler DS: The Sensitive Nervous System; Adelaide: Noigroup Publications, 2000.

8) Turl SE, George KP: Adverse neural tension: a factor in repetitive hamstring strain? J Orthop Sports Phys Ther, 1998, 27: 16-21. [Medline]

9) You JK, Kim DS: Electromyography; Seoul: Korea Medical Book Publisher, 2009, pp 349-350.

10) Lee KM, Ra YJ: Estimation of reference values of median nerve conduction study: a meta-analysis. J Korean Acad Rehabil Med, 2002, 26: 717-725.

11) Coppieters MW, Alshami AM: Longitudinal excursion and strain in the median nerve during novel nerve gliding exercises for carpal tunnel syndrome. J Orthop Res, 2007, 25: 972-980. [Medline] [CrossRef]

12) Henrikson JD: Conduction velocity of motor nerves in normal subjects and patients with neuromuscular disorders. Minnesota University, Master's Thesis, 1956.

13) Johnson EW, Olsein KJ: Clinical value of motor nerve conduction velocity determination. JAMA, 1960, 172: 2030-2035. [CrossRef]

14) Halar EM, DeLisa JA, Soine TL, et al.: Nerve conduction studies in upper extremities: skin temperature correction. Arch Phys Rehab Med, 1983, 64: $412-416$.

15) Kim JS, Lee HO, Ahn SY, et al.: An electrophysiologic study on the median digital nerves in healthy adults. J Korean Soc Phys Ther, 2005, 17: 329-338.

16) Gilliatt RW: Electrophysiology of peripheral neuropathies: an overview. Muscle Nerve, 1982, 5: S108-S116. [Medline]

17) Kleinrensink GJ, Stoeckart R, Mulder PG, et al.: Upper limb tension tests as tools in the diagnosis of nerve and plexus lesions. Clinl Biomech (Bristol, Avon), 2000, 15: 9-14. [Medline] [CrossRef]

18) Bolton CF, Sawa GM, Carter K: The effect of temperature on human compound action potentials. J Neural Neurosurg Psych, 1981, 44: 407-413. [CrossRef]

19) Park JW, Lee HS, Bae SS, et al.: The review of mobilization of the nervous system. J Korean Soc Phys Ther, 2000, 12: 153-161.

20) Park JW, Kim SH, Nam KS, et al.: Effect of the upper limb nerve mobilization on functional recovery in hemiplegic patients following stroke. J Korean Acad Univ Trained Phys Therapists, 2001, 8: 29-39.

21) Anderson M, Tichenor CJ: A patient with De Quervain's tenosynovitis Phys Ther, 1994, 74: 314-326. [Medline]

22) Rozmaryn LM, Dovelle S, Rothman ER, et al.: Nerve and tendon gliding exercise and conservative management of carpal tunnel syndrome. J Hand Ther, 1998, 11: 171-179. [Medline] [CrossRef]

23) Kim MK, Hwangbo K, Jang JS, et al.: Effects of the median nerve mobilization on change of nerve conduction velocity, grip strength and pain in patients with carpal tunnel syndrome. Korea J Exerc Rehabil, 2011, 7: 113-121.

24) Yoon YD: Effects of the median nerve mobilization on change of grip strength and pain in patients with carpal tunnel syndrome. Catholic University of Busan, Master's Thesis, 2009. 